\title{
BENEFICIATION STUDIES ON TERI SANDS, TAMILNADU BY USING ADVANCED AIR CYCLONE CLASSIFIER
}

\author{
T. Laxmi ${ }^{1}$ and R. Bhima Rao ${ }^{2, \#}$ \\ ${ }^{1}$ CSIR -IMMT, Bhubaneswar-751 013, India \\ ${ }^{2}$ Chairman, Institution of Engineers India, Odisha State Centre, \\ Bhubaneswar, 751001, India
}

(Received: October 23, 2013; Accepted: May 27, 2014)

\begin{abstract}
In this paper an attempt is made on Teri sands Tamilnadu for removal of fines as well as concentration of heavy minerals by using an advanced air cyclone with VSK separator. The studies reveal that VSK separator can classify the mineral raw materials at first instance and later on subsequent operations it is observed that a mineral concentration also achieved.
\end{abstract}

Key words: VSK Separator, classification, static, dynamic, teri sands, heavy minerals, slimes, pyriboles.

\section{Introduction}

Air cyclones are one type among the advanced air classifiers. Air cyclones are identical in construction and operation to hydro cyclones. In mineral processing industries air cyclones are used for closed circuit dry grinding system where classification of coarse and fine particles is to be effected and coarse particles fed back to the system. However it has no known applications for separation of heavy and light minerals and slimes. Thus any cyclone design to satisfy the requirement of size classification, recovery of fine dust and concentration of minerals is in great demand for use in dry circuits. VSK separator is one of the air classifiers with a combination of static and dynamic separators to satisfy the above requirements. However, the unit has been accepted in cement industries all over the world and also in some of the fertilizer industries. Some exploratory work has been done at CSIR-IMMT, Bhubaneswar on dry separation studies with reference to separation of fines and preconcentartion of iron ore fines, beach sans, red sediments and lime stone [16]. However, so far no attempt is made at any other organisations except IMMT for reduction of fines and upgradation of total heavy minerals present in sand by using VSK dry classifier. In view of this in present study attempts are made on Teri sand, Tamilnadu for removal of fines and dry beneficiation using VSK separator.

\section{Materials and methods}

\subsection{Raw material}

About two tons of pre concentrated Teri sand was received from M/s TATA STEEL from Tirunelveli Dist., Tamilnadu.

The sand is reddish in colour and contains $0.5 \%$ moisture. It may be noted here that the terminology "Teri" is regional language of Tamilnadu, which means Red. Hence, red sands are known as Teri sands at Tamilnadu.

\#Corresponding author: bhimarao@gmail.com 


\subsection{Studies on VSK separator}

The present study deals with the separation of slimes as well as dry beneficiation studies on ROM by using VSK air classifier. The pilot plant of VSK separator, model no. SKS VS 10.4 , designed by M/s Humbolt Wedag India, was used in the present study. Principle of operation of advanced air cyclone is shown in Fig. 1. The as received feed sample was sub sampled using standard riffler sampler. At first sample was subjected to VSK separator in batch at different conditions of cage wheel, screw feeder at constant air rate of $49 \mathrm{~Hz}$ to optimize the equipment.

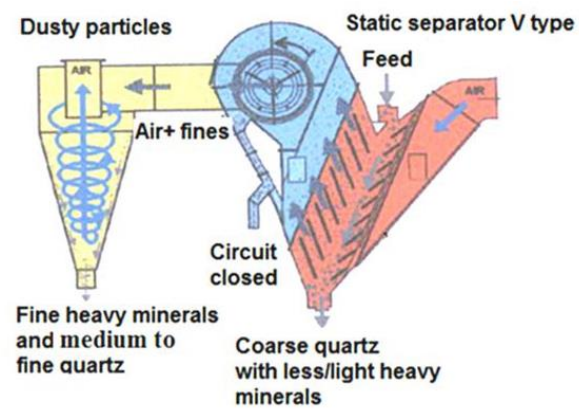

Figure 1. Principle of operation of advanceed air cyclone (VSK separator- static and dynamic separator with cyclone)

In the present study, the central composite design (CCD) was chosen to find out the relation between the two response functions such as grade and recovery and two variables of VSK such as cage wheel and screw feeder and at the same time, MATLAB 7.12.0 was chosen to find out the optimum condition based on experimental design given by the CCD.

Large scale continuous beneficiation studies were carried out at the optimized conditions of cage wheel and screw feeder. During experiments, the feed sample was subjected to rougher VSK separator for obtaining coarse and fine materials. Each factor at three different levels was studied.
The variables at different levels chosen for CCD are given in Table 1.

Table 1. The level of variables chosen for Central Composite Design

\begin{tabular}{|l|c|c|c|c|}
\hline \multirow{2}{*}{ Variables } & \multirow{2}{*}{ Symbol } & \multicolumn{3}{|c|}{ Coded variable level } \\
\cline { 3 - 5 } & & Low & Centre & High \\
\cline { 3 - 5 } & $\mathrm{x}_{1}$ & 400 & 800 & +1 \\
\hline $\begin{array}{l}\text { Cage } \\
\text { wheel, } \\
\text { rpm }\end{array}$ & & 800 & 1000 & 1200 \\
\hline $\begin{array}{l}\text { Screw } \\
\text { feeder, } \\
\text { rpm }\end{array}$ & $\mathrm{x}_{2}$ & & & \\
\hline
\end{tabular}

\subsection{Software applications}

\subsubsection{Central Composite Design}

In statistics, a central composite design is an experimental design, useful in response surface methodology, for building a second order (quadratic) model for the response variable without needing to use a complete three-level factorial experiment. CCD for two factors at three levels with $\alpha=1$, equivalent to a $3^{2}$ factorial design, was chosen as the experimental design. This is an effective second-order experimental design associated with a minimum number of experiments to estimate the influence of individual variables (main effects) and their second-order effects. To investigate the factors systematically, a central composite design was employed.

As shown in Equation-1, a statistical model incorporating multi regression analysis was used to evaluate the responses.

$Y=\beta_{0}+\beta_{1} X_{1}+\beta_{2} X_{2}+\beta_{3} X 1^{2}+\beta_{4} X_{2}^{2}+\beta_{5} X_{1} X_{2}$

Initially, the samples were subjected to VSK separator at different conditions to optimize the equipment. All experiments were carried out in a batch. 
During this process, the sample was continuously supplied to the feeder for maintain the constant air dynamics $(49 \mathrm{~Hz})$. Samples were collected at a period of ten minutes for each operating variables.

\subsubsection{MATLAB 7.12}

MATLAB, which stands for MATrix LABoratory, is a state-of-the-art mathematical software package, which is used extensively in both academia and industry. It is an interactive program for numerical computation and data visualization, which along with its programming capabilities provides a very useful tool for almost all areas of science and engineering. MATLAB is used for following reasons,

$>$ Computations, including linear algebra, data analysis, signal processing, polynomials and interpolation, numerical integration (quadrature), and numerical solution of differential equations.

- Graphics, in 2-D and 3-D, including colour, lighting, and animation.

\subsection{Characterization}

The detailed physical and chemical characterization studies of ROM and slimes were done. Mineralogical studies were carried out by X-ray Diffraction (PANalytical, X-Pert $\mathrm{X}$-ray powder diffractometer with $\mathrm{Mo}-\mathrm{K} \alpha$ radiation). Elemental analyses of the samples were carried out by XRF (PANalytical; PW2440 (MagiX PRO).

\section{Results and discussion}

\subsection{Characterization of feed sample}

The received sand sample contains $0.5 \%$ moisture, free flow character and reddish in colour. This is due to coating of fine ferruginous materials on the sand. The physical properties of feed sample such as size analysis, sink float studies and chemical analysis of slimes are given in Table 2 . The data indicate that the feed sample contains 8.8 $\%$ THM in which very heavy minerals (such as ilmenite, zircon, rutile, garnet, monazite etc) are $5.5 \%$ by weight and light heavy minerals (such as sillimanite and pyrabols) are $3.3 \%$ by weight. The light mineral such as quartz is accounting for $91.2 \%$ by weight. The total magnetic minerals are $5.2 \%$ by weight which may be due to ilmenite and minor amount of other minerals such as garnet, monazite etc. The $-63 \mu \mathrm{m}$ size fraction is $2.3 \%$ by weight. The moisture content of feed sample is $0.5 \%$ and the $\mathrm{d}_{80}$ passing size of the feed is 320 microns.

Table 2. Physical properties of feed sample

\begin{tabular}{|l|l|}
\hline Bulk density, $\mathrm{g} / \mathrm{cm}^{3}$ & 1.54 \\
\hline True density, $\mathrm{g} / \mathrm{cm}^{3}$ & 3.0 \\
\hline Porosity, $\%$ & 48.7 \\
\hline Angle of repose, degree & 33.7 \\
\hline $\mathrm{d}_{80}$ passing size, $\mu \mathrm{m}$ (Wet method) & 320 \\
\hline Moisture content, \% & 0.5 \\
\hline$-63 \mu \mathrm{m}, \mathrm{Wt} ., \%$ & 2.3 \\
\hline $\mathrm{Fe}_{2} \mathrm{O}_{3}$ in -63 $\mu \mathrm{m}, \mathrm{Wt} \%$ & $8.8-9.0$ \\
\hline Total Heavy Minerals (THM) Wt \% & 8.8 \\
\hline Total Magnetic Minerals (TMM) Wt \% & 5.2 \\
\hline Very Heavy Minerals (VHM) Wt \% & 5.5 \\
\hline Light Heavy Minerals (LHM) Wt \% & 3.3 \\
\hline Quartz, Wt \% & 91.2 \\
\hline
\end{tabular}

The bulk density of the feed is $1.54 \mathrm{~g} / \mathrm{cc}$ and specific gravity of the sample is 3.08 . The overall porosity is calculated on the basis of density and specific gravity is $48.7 \%$.

The mineralogical modal analysis of the deslimed red sand sample is shown in Fig. 2. It indicates that the red sand sample mainly contains quartz (91.2\%), followed by ilmenite (5.2\%), zircon (1.6\%), sillimanite (1.5\%), whereas rutile, garnet, monazite and other minerals $(0.5 \%)$ are present in small quantities. 
The mineralogical data indicate that the specific gravity difference between heavy minerals such as ilmenite, rutile, zircon, sillimanite etc and gangue mineral quartz is very much significant.

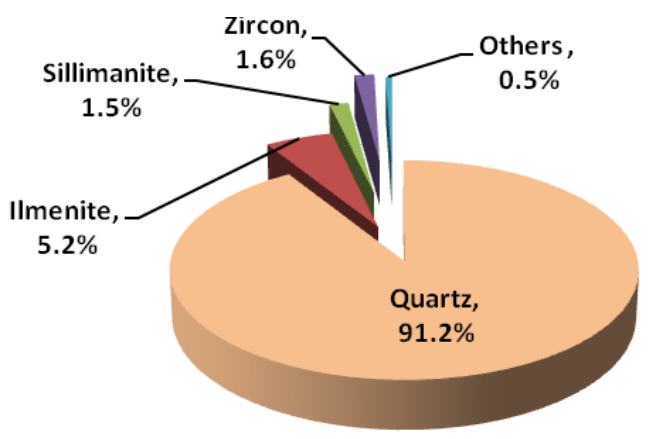

Figure 2. Modal analysis of deslimed feed of Teri sands, Tamilnadu

The size analysis of as received sand (feed to VSK separator) by dry method and wet method is shown in Fig.3. The results of these studies indicate that the $\mathrm{d}_{80}$ passing size obtained by both dry and wet sieving is 390 $\mu \mathrm{m}$ and $320 \mu \mathrm{m}$ respectively. However, the fines $(-63 \mu \mathrm{m})$ obtained by dry and wet size analysis are distinctly differ. The -63 micron size fraction obtained by dry classification is $2.3 \%$ by weight, whereas by wet size classification is $6.2 \%$ by weight.

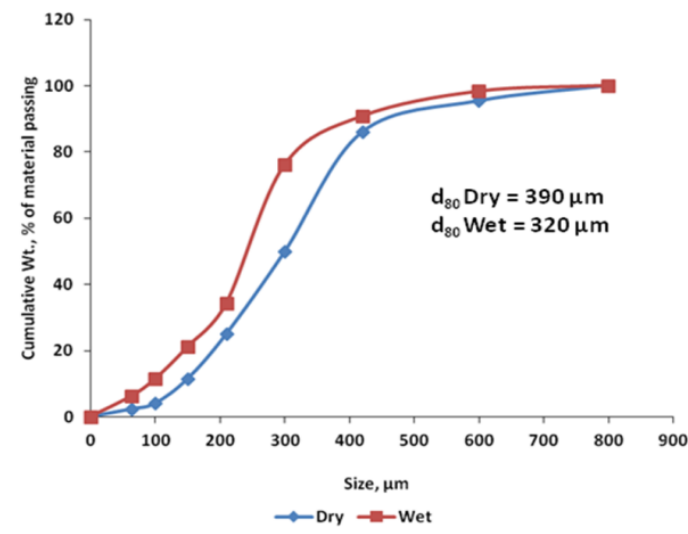

Figure 3. Size analysis of as received sand

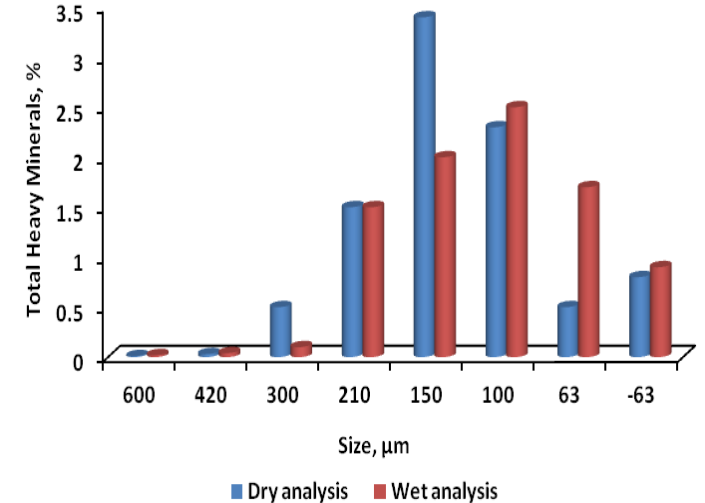

Figure 4. Distribution of heavy minerals in close size fractions

The distribution of heavy minerals in individual size fractions of wet as well dry analysis is shown in Fig.4. It clearly, indicates that in case of dry analysis maximum percentage of heavy minerals is present in size fraction of $150 \mu \mathrm{m}$, where as in case of wet analysis maximum percentage of heavy minerals are present in size fraction of 100 $\mu \mathrm{m}$. The total heavy minerals present in both analysis is determined from sink float studies which is in the range of 8.8 to $9.0 \%$ (THM).

The XRD diffraction pattern of scrubbed feed and slimes are shown in Fig. 5. The XRD pattern confirms the findings that the given sample contains mostly quartz than ilmenite followed by minor amounts of sillimanite, zircon, rutile, monazite etc.

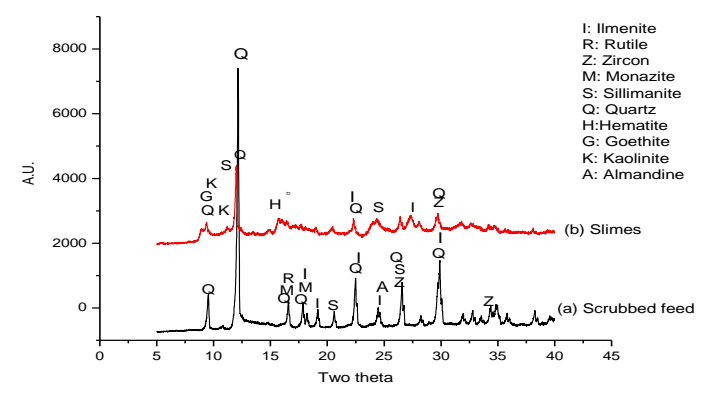

Figure 5. XRD diffraction pattern of scrubbed feed and slimes 
The complete chemical analysis of the slimes $(-63 \mu \mathrm{m})$ shown in Table 3 indicate that the sample contains $77.6 \% \mathrm{SiO}_{2}$ and $8.8 \%$ $\mathrm{Al}_{2} \mathrm{O}_{3}$, accounting for quartz and clay group of minerals.

Table 3. Chemical analysis of slimes $(-63 \mu \mathrm{m}$ size fraction) present in feed

\begin{tabular}{|c|c|}
\hline Elements & Percentage \\
\hline $\mathrm{SiO}_{2}$ & 77.6 \\
\hline $\mathrm{Fe}_{2} \mathrm{O}_{3}$ & 8.8 \\
\hline $\mathrm{Al}_{2} \mathrm{O}_{3}$ & 4.1 \\
\hline $\mathrm{TiO}_{2}$ & 5.2 \\
\hline $\mathrm{CaO}$ & 0.2 \\
\hline $\mathrm{MgO}$ & 0.1 \\
\hline
\end{tabular}

Table 4. Size and Iron analysis of slimes (-63 $\mu \mathrm{m}$ size fraction, $2.3 \%$ by wt in the feed)

\begin{tabular}{|c|c|c|}
\hline Size, $\mu \mathrm{m}$ & $\mathrm{Wt} \%$ & $\mathrm{Fe}_{2} \mathrm{O}_{3}, \%$ \\
\hline$-63+45$ & 37.5 & 7.4 \\
\hline$-45+30$ & 29.0 & 4.4 \\
\hline$-30+20$ & 4.1 & 10.0 \\
\hline$-20+10$ & 2.1 & 20.5 \\
\hline-10 & 27.3 & 14.0 \\
\hline Head & 100.0 & 8.8 \\
\hline
\end{tabular}

The sample contains $5.2 \% \mathrm{TiO}_{2}$ which indicates the presence of ilmenite or rutile in the sample.

The size analysis and iron analysis of each close size fractions of slimes shown in Table 4 indicate that the iron is mostly present in the finer size fraction specially at $-20+10$ micron size.

\subsubsection{Optimization studies (Response surface methodology)}

A two-factor central composite design was used to determine the response for the grade and recovery of total heavy minerals by optimizing VSK separator. The cage wheel $\left(x_{1}\right)$ and screw feeder $\left(x_{2}\right)$ were two independent variables studied to predict the responses $\left(Y_{1}\right.$ and $\left.Y_{2}\right)$. Using the relationships in Table 1, the coded levels of the variables for each of the experiments in the design matrix were calculated. The experimental results and predicted results by software is given in Table 5.

Table 5. Experimental results and predicted results given by response surface methodology

\begin{tabular}{|c|c|c|c|c|c|c|}
\hline \multirow{2}{*}{$\begin{array}{c}\text { Expt. } \\
\text { No. }\end{array}$} & \multirow{2}{*}{$\begin{array}{c}\text { Cage } \\
\text { wheel, } \\
\text { rpm }\end{array}$} & \multirow{2}{*}{$\begin{array}{c}\text { Screw } \\
\text { feeder, } \\
\text { rpm }\end{array}$} & Grade, $\%$ & Recovery, $\%$ & Grade, $\%$ & Recovery, $\%$ \\
\cline { 5 - 7 } & 800 & 1000 & 8.1 & 36.5 & 8.1 & 36.7 \\
\hline 1 & 1200 & 800 & 5.9 & 46.5 & 5.8 & 47.3 \\
\hline 2 & 1200 & 1200 & 7.9 & 38.9 & 8 & 37.7 \\
\hline 3 & 800 & 1000 & 8.1 & 36.5 & 8.1 & 36.7 \\
\hline 4 & 400 & 800 & 7.2 & 40.2 & 7.1 & 41.5 \\
\hline 5 & 800 & 1000 & 8.1 & 36.5 & 8.1 & 36.7 \\
\hline 6 & 400 & 1200 & 7.5 & 39.5 & 7.7 & 38.8 \\
\hline 7 & 800 & 1000 & 8.1 & 36.5 & 8.2 & 36.4 \\
\hline 8 & 1200 & 1000 & 7.5 & 38.5 & 7.5 & 38.9 \\
\hline 9 & 800 & 1200 & 8.7 & 35.6 & 8.4 & 37.4 \\
\hline 10 & 800 & 800 & 6.8 & 45.6 & 7 & 43.5 \\
\hline 11 & 400 & 1000 & 8 & 37.2 & 7.9 & 36.6 \\
\hline 12 & 800 & 1000 & 8.1 & 36.5 & 8.2 & 36.4 \\
\hline 13 & 800 & 1000 & 8.1 & 36.5 & 8.2 & 36.4 \\
\hline 14 & & & & & & \\
\hline
\end{tabular}


From the experimental results listed in Table 5 and Eq. (1), the second-order response functions representing the grade and recovery of total heavy minerals by using VSK separator. This could be expressed as

Model equation for grade:

$$
\begin{aligned}
& Y_{1}=8.12-0.23 x_{1}+0.70 x_{2}-0.46 x_{1}{ }^{2}-0.46 x_{2}{ }^{2}+0.43 x_{1} x_{2} \\
& \text { Model equation for recovery: } \\
& Y_{2}=36.54+1.17 x_{1}-3.05 x_{2}+1.08 x_{1}{ }^{2}+3.83 x_{2}{ }^{2}-1.72 x_{1} x_{2}
\end{aligned}
$$

The actual and predicted values of responses obtained using model equations (Eqs. 2 and 3) is presented in Fig. 6. Predicted values correlated very well with the experimental results, indicating a good fitness $\left(\mathrm{R}^{2}\right.$ value of 0.96 for the grade and $\mathrm{R}^{2}$ value of 0.91 for the recovery).

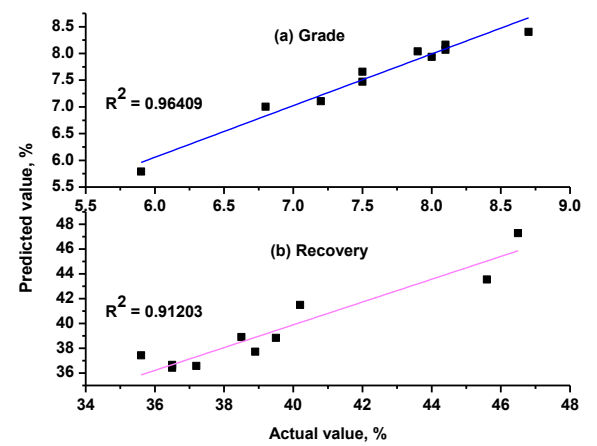

Figure 6. Relation between actual (experimental) and predicted values for grade and recovery

\subsubsection{Effect of variables on the res- ponses}

In order to gain a better understanding of the results, Figs. 7(a) and 7(b) show 3D response surface plots, which describe the effect of grade and recovery with change in variable parameters such as cage wheel and screw feeder at constant air rate of $49 \mathrm{~Hz}$.

Fig. 7(a) shows the effect of cage wheel and screw feeder on grade of total heavy minerals. It is observed that higher grade is obtained at higher level of screw feeder and at centre level of cage wheel. Similarly, Fig. 7(b) shows the effect of cage wheel and screw feeder on recovery of total heavy minerals. It is observed that higher recovery is obtained at lower level of screw feeder and higher level of cage wheel.

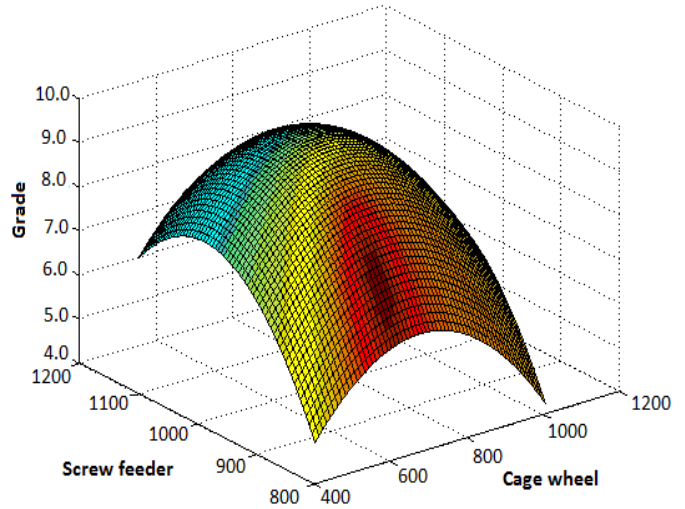

(a)

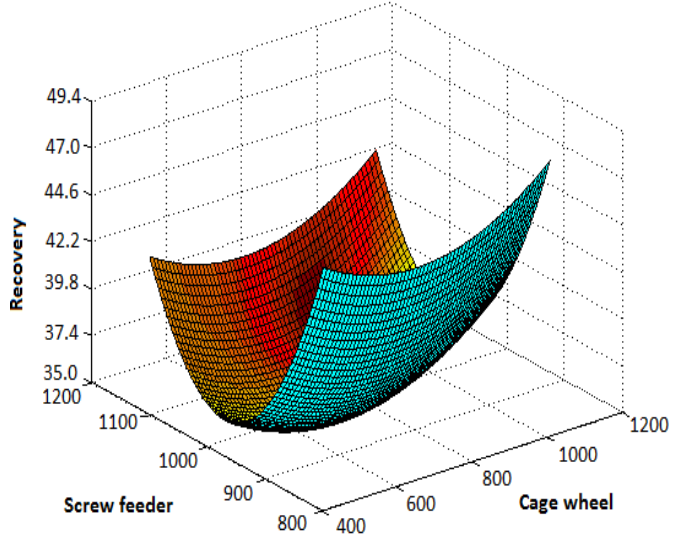

(b)

Figure 7. Effect of cage wheel and screw feeder on VSK separator for (a) grade and (b) recovery of total heavy minerals 


\subsubsection{Optimization}

The objective of response surface optimization is to find a desirable location in the design space. This could be a maximum, a minimum, or an area where the response is stable over a range of factors. In this research, quadratic optimization technique was used for optimization of response equations using MATLAB 7.12 software.

It is observed that maximum grade of $8.3 \%$ is achieved at $800 \mathrm{rpm}$ cage wheel and $1200 \mathrm{rpm}$ screw feeder. Similarly, maximum recovery of $37.86 \%$ is achieved $1200 \mathrm{rpm}$ cage wheel and 800 rpm screw feeder.

\subsubsection{Design of experiments for optimizing the VSK separator to recover fines}

By using above optimum conditions, VSK separator was operated for as received feed sample. The VSK unit is performing well at
$800 \mathrm{rpm}$ cage wheel, $1200 \mathrm{rpm}$ screw feeder and air rate of $49 \mathrm{~Hz}$. The flowsheet with material balance for recovery of fines from Teri sands Tamilnadu by using VSK separator is shown in Fig.8. The flowsheet contains one rougher and two cleaner units. The results of rougher VSK separator show that the coarse fraction contains $86.6 \%$ by weight with $1.1 \%$ by weight of fines, where as the fine fraction contains $13.4 \%$ by weight with $10.0 \%$ by weight of fines. Similarly, the first cleaner unit of VSK separator show that the coarse fraction contains $93.8 \%$ by weight with $0.5 \%$ fines and the fine fraction contains $6.2 \%$ by weight with $9.5 \%$ fines. At next stage, the rougher fines mixed with fines of first stage cleaner unit and subjected to second stage cleaner VSK unit. The results of second stage cleaner VSK unit indicate that, coarse fraction contains $68.0 \%$ by weight with $2.7 \%$ fines and the fine fraction contains $32.0 \%$ by weight with $25.1 \%$ fines.

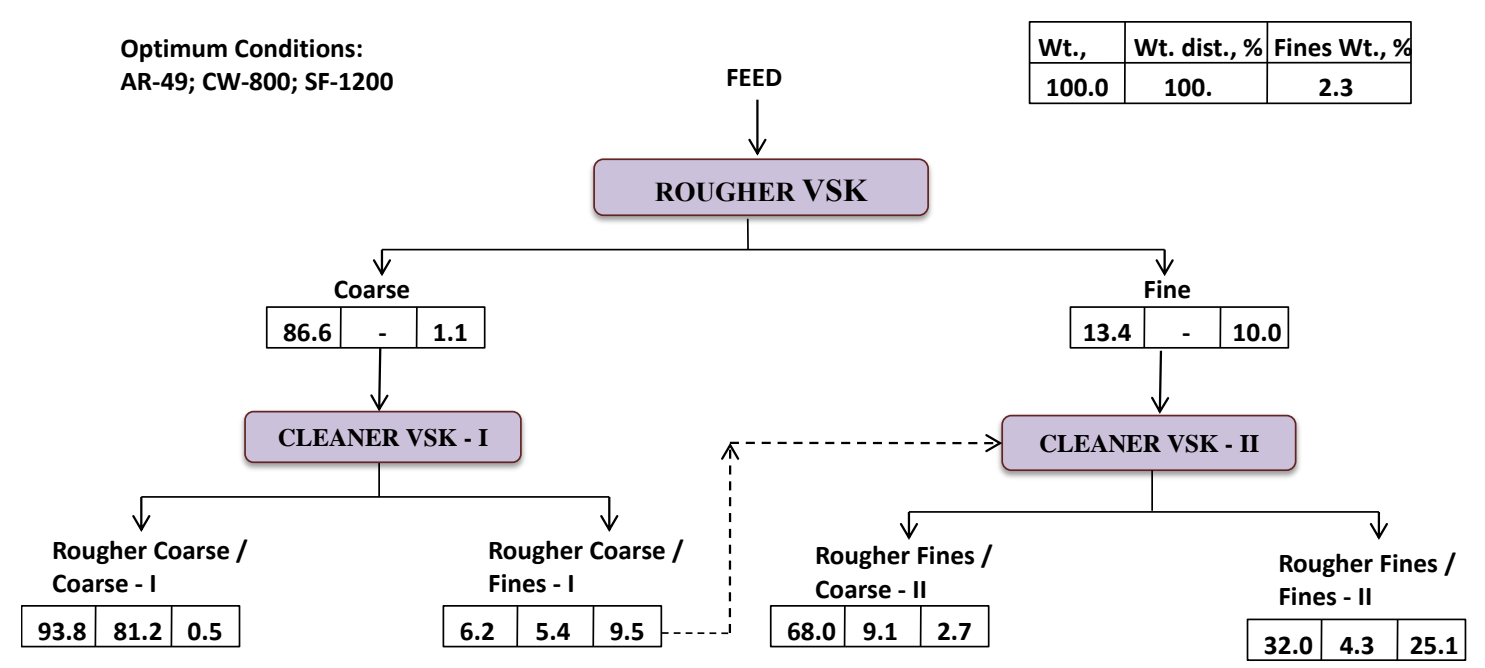

Figure 8. Flowsheet with material balance for recovery of fines using VSK separator

The flowsheet with material balance for recovery of THM from Teri sands Tamilnadu by using VSK separator is shown in Fig. 9. The flowsheet contains one rougher and two cleaner units. The results of rougher VSK separator show that the coarse fraction contains $86.6 \%$ by weight with $8.7 \%$ grade of THM. 
Where as the fine fraction contains $13.4 \%$ by weight with $9.5 \%$ grade of THM. Similarly, the first cleaner unit of VSK separator show that the coarse fraction contains $81.2 \%$ by weight with $8.2 \%$ grade of THM and the fine fraction contains $5.4 \%$ by

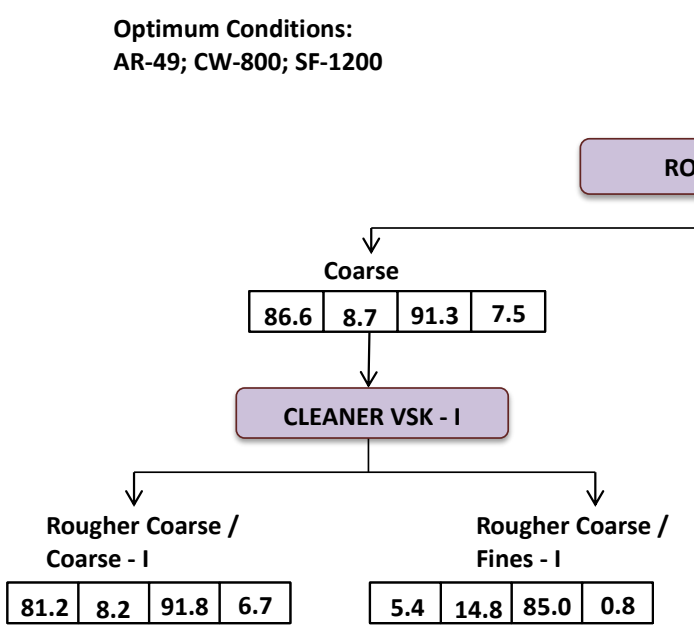

weight with $14.8 \%$ grade of THM. The results of second stage cleaner VSK unit indicate that, coarse fraction contains $9.1 \%$ by weight with $9.9 \%$ grade of THM and the fine fraction contains $4.3 \%$ by weight with $9.3 \%$ grade of THM.

\begin{tabular}{|c|c|c|c|}
\hline Wt.,\% & Sink,\% & Quartz, \% & THM,\% \\
\hline 100.0 & 8.8 & 91.2 & 8.8 \\
\hline
\end{tabular}

OUGHER VSK

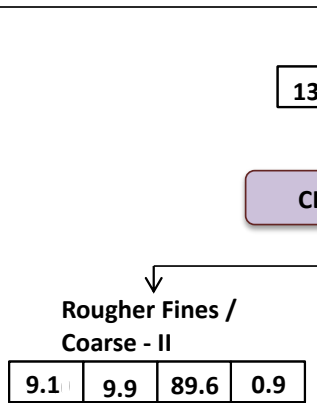

Fine
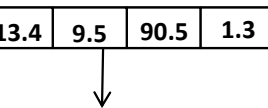

CLEANER VSK - II

Figure 9. Flowsheet with material balance for recovery of THM using VSK separator

\subsubsection{Characterization of products}

Typical XRD patterns of VSK products such as rougher coarse, cleaner fines and fines from recirculation of coarse shown in Figs. 10 to 13 indicate that rougher coarse light heavy minerals contain mostly sillimanite, where as the cleaner fines contain mostly pyrobols (>3.2 sp.gr) such as pyroxene and amphibole silicate minerals which has got no commercial value. Hence these fines can be rejected from the circuit.

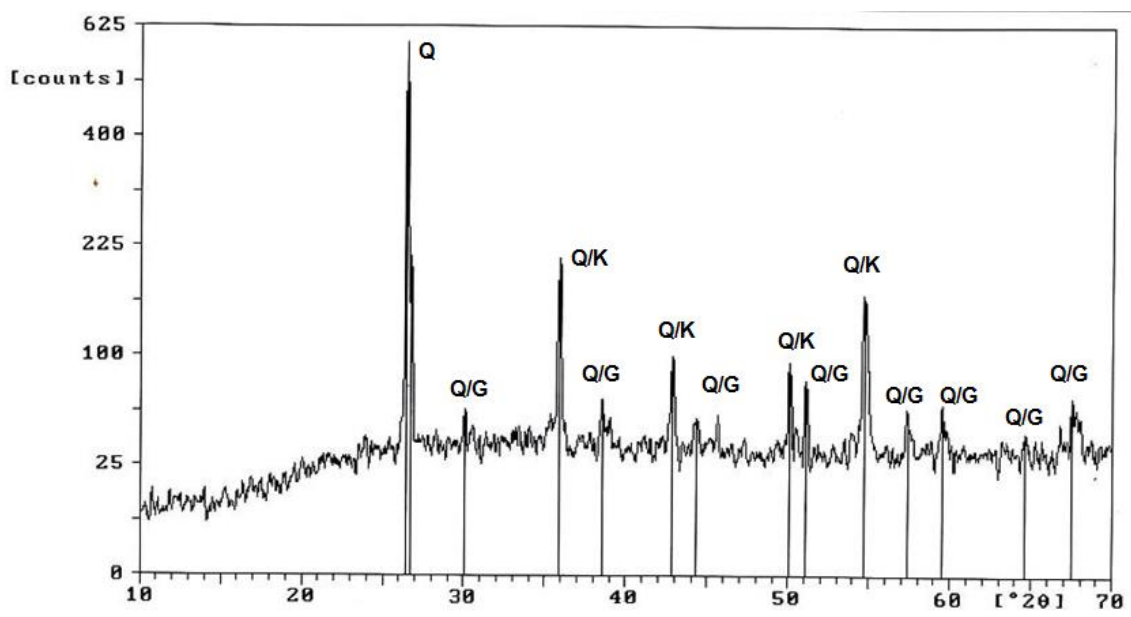

Figure 10. XRD of rougher coarse for LHM 


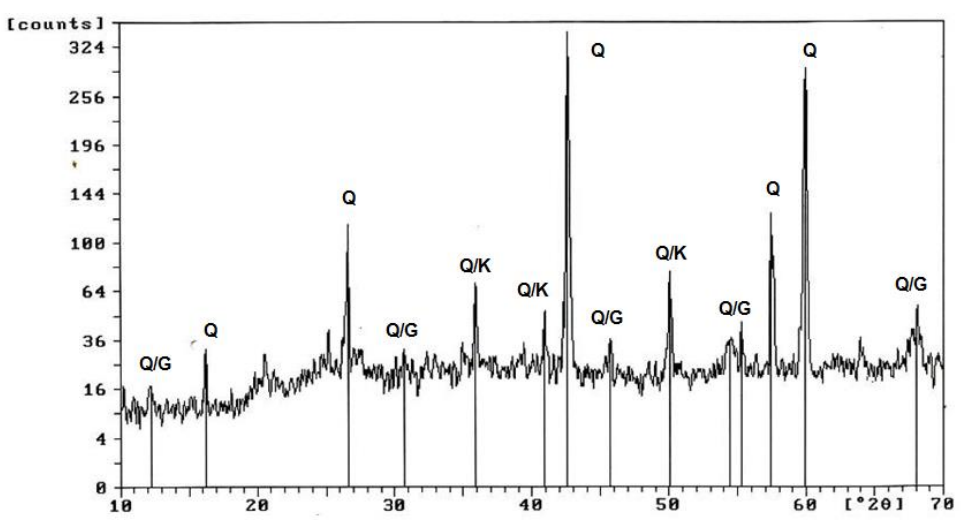

Figure 11. XRD of rougher fines for LHM

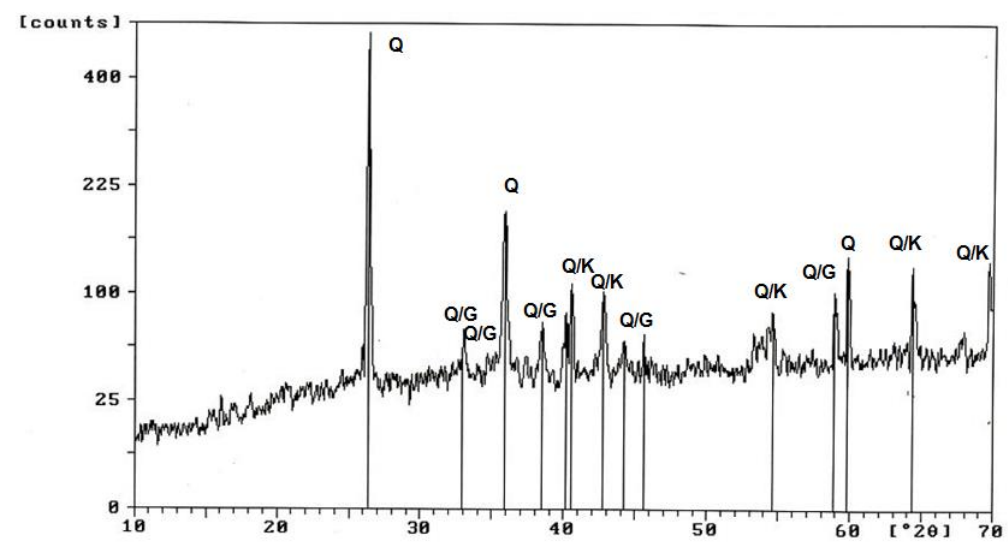

Figure 12. XRD of cleaner coarse for LHM

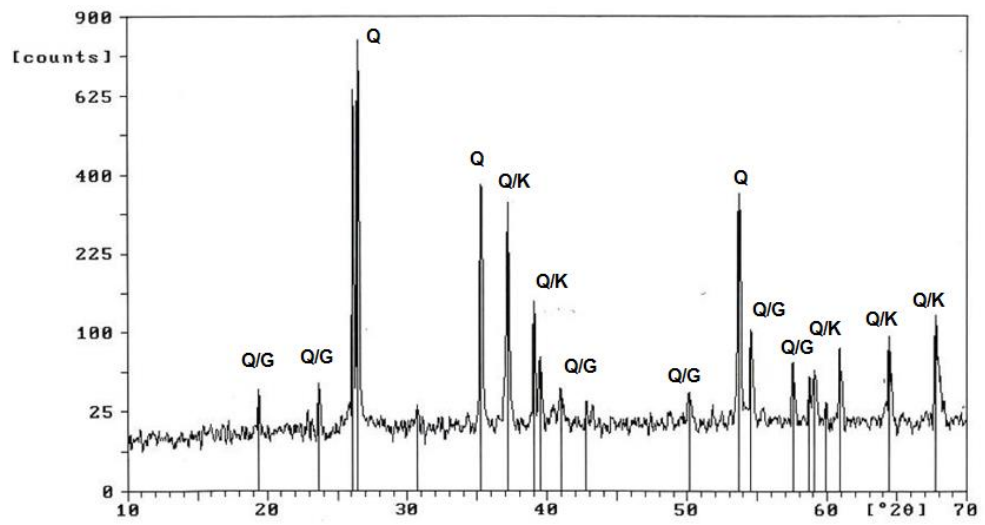

Figure 13. XRD of cleaner fines for LHM

The summary of results confirm that the VSK separator can remove fines and also assisting in removing of some light heavy minerals like pyroxenes and amphibols, which has no commercial value and poses problems in downstream mineral processing. 


\section{Conclusions}

The following conclusions are drawn from the experimental studies carried out on Teri sand Tamilnadu by using advanced air cyclones, VSK separator.

- The mineralogical distribution of sand sample reveals that the ROM sample contains $91.2 \%$ quartz (bromoform float), $3.3 \%$ [(Di-iodo methane), light heavy minerals (LHM, such as pyrobols)] and $5.5 \%$ very heavy minerals (Di-iodo methane sink).

- The results of VSK unit for reduction of slimes indicate that, coarse fraction contains $68.0 \%$ by weight with $2.7 \%$ fines and the fine fraction contains $32.0 \%$ by weight with $25.1 \%$ fines.

- Similarly, the results of second stage cleaner VSK unit for recovery of THM indicate that, coarse fraction contains $9.1 \%$ by weight with $9.9 \%$ grade of THM and the fine fraction contains $4.3 \%$ by weight with $9.3 \%$ grade of THM.

- The results confirm that the VSK separator can remove fines and also assisting in removal of some light heavy minerals like pyroxenes and amphibols, which has no commercial value and poses problems in downstream mineral processing.

\section{Acknowledgments}

The authors are thankful to the Director, Institute of Minerals and Materials Technology (CSIR), Bhubaneswar for giving permission to use laboratory facilities. One of the authors Ms. T. Laxmi is thankful to CSIR for granting Senior Research Fellowship.

\section{References}

[1] Patnaik, S., Satapathy, D., Vasumathi, N., Reddy, P.S.R. and Bhima Rao, R., (2008) Preliminary studies on applications of advanced air cyclones for dry beneficiation of coking coal fines,. In Proc. Conference of Technical Annual 49th Session of the Institution of Engineers (India), Orissa State Centre, Bhubaneswar, p. 197-207.

[2] Bhima Rao, R., Reddy, P. S. R., Eswaraiah, C., Tripathy, H.K. and Satapathy, D. (2009) Feasibility Studies on Reduction of Silica Content from Sattankulam Limestone by using VSK Separator. IMMT Report No: T/ MP/ 718/Aug/2009.

[3] Bhima Rao, R., Reddy, P. S.R., Eswariah, C., Rao, D. S. and Mishra, B. K. (2012) Studies on the use of advanced air cyclone for separation of zircon and sillimanite concentrates from non-conducting non-magnetic fraction of IREL mineral separation plant. Chtrapur, Odisha, IMMT Report No: 881/MP/SSP36/July/2012.

[4] S.K., Biswal, Sahu, A.K., Parida, A., Reddy, P.S.R. and Misra, V.N., (2002) Prospects of dry beneficiation of Indian high ash non-coking coal - A review. Journal of Mines, Metals and Fuels, 51, 53-57.

[5] Dwari, R. K. and Rao, K. Hanumantha, (2007) Dry Beneficiation of Coal - A Review. Mineral Processing and Extractive Metallurgy Review, 28 (3) $177-234$.

[6] Routray, S. and Bhima Rao, R., (2013) Preconcentartion of heavy minerals from beach and dune sands by using advanced air cyclone. Multi Discipli-nary Edu Global Quest (Quarterly), 2 (6). 